\title{
A changing paradigm of interpersonal communication in divorce family
}

\author{
Lucy Pujasari Supratman ${ }^{1, *}$ \\ ${ }^{1}$ Faculty of Communication and Business, Communication Department, Telkom University, \\ Telekomunikasi Street Number 1, Bandung-West Java, Indonesia.
}

\begin{abstract}
Indonesia is a country that embraces the Eastern Culture. The Eastern Culture identity attached to each family along with their values and norms. In the modernization era, there is a changing paradigm on looking at the value of family unity. The stigma in divorced families is no longer viewed negatively. It has been considered as nowadays lifestyle. According to statistics data from the Religious Affairs Ministry, the divorce rate in Indonesia is increasing. The results of this study are the changing paradigm of agreeing the parent's divorced decision to teenagers and the changing social interaction in the family. It has changed the interpersonal communication between the single parents and their young teenagers. The teenagers experience confusion to communicate in the beginning of the divorce with both parents. They traumatized, isolated themselves, and breakout. Effective interpersonal communication just started to shape after the single parents succeeded to adapt to a new social family pattern. Teenagers begin to shape their positive identity after it. While the negative identity is shaped to the teenagers who fail to communicate with their single parents.
\end{abstract}

\section{Introduction}

Family is the smallest social community formation. It is the smallest organization in society and the first container for psychological development for children. They will receive their first education on various orders of life in the family. All members of family consist of father, mother and children who obtain different roles. In general, father acts to protect and provide family needs. While mother role is to take care of the household and educate the children. Children role in the family is to accomplish the education. Parents must give good education to children, so they will have a bright future. Each role is executed according to the function in the family. The role of the family should be built together to foster harmonious family.

Parents will introduce the children to religious values, norms and community life as the foundation for them to socialize in social environment. In addition, parents also become a major encouragement when children need the support in life. Communication of father,

\footnotetext{
*Corresponding author: doktorlucysupratman@gmail.com/lucysupratman@telkomuniversity.ac.id
} 
mother and children will be interconnected at any time in social interaction. Social interaction in the family occurs because they need each other.

Communication within a family is an important thing to be loved. When parents can no longer create good communication for children, the family atmosphere will not be conducive. The estrangement will create a communication gap. Personal ego of parents will sharpen into unsolved conflict to result in divorce. Parents have formed a failure in maintaining the balance of the family because they are not able to resolve the existing conflicts. The family on parents who choose the divorce solution to end the conflict has changed the social family hierarchy. It only consists of a father and the children, or mother and the children. Segrin [1] gave the termination of binuclear family, which is father or mother turned into a single parent. Parents no longer live together in the house. They should separate into non-intact families. A change in family form makes the gathering intensity of parents and children getting reduced.

This study is aimed to describe the changing paradigm of social interaction in divorce family. I would like to explain the formation of interpersonal communication between teenagers and their single parents after experiencing the divorce in globalization era.

\section{Literature Review}

There are many research about the interpersonal communication in divorce family have been conducted earlier. Most of all were published by using quantitative research method. As Fagan [2] stated on his research that the divorce brought a great impact to the prominent environment, such as family, worship place, school, marketplace and government. Those things were the main institution to create harmonization and to eliminate the side effect of the divorce to the children. Children were considered to be the victim in this research. It suggested that the academician, religion leader and government put the responsibility to the development of children from divorce family on their future education, morality, emotional, and physical. Whereas [3] Belinda et al elaborated their research about the impact of divorce to children in United States of America. Their research subject was teenagers from divorce family. Mostly, they refuse their parents separation. Moreover, teenagers from divorce family tend to follow the steps of their parent divorce rather than those parents who remain together. It was caused by teenagers' difficulty in adapting new family atmosphere. Their experiences as teenagers from divorce family effected family member health, outcomes and teenagers welfare. While [4] Kasoman stated that the student's education performances were influenced by divorce family situation. Students' performances were not able to get good marks in the school subjects. The research was located in some Mbala Disctrict schools. This research recommended five atmospheres to have the responsible in reducing the divorce rate to the edge. The more strengthen family bonding will be increased human resource capacity in the environment.

\section{Methodology}

The methodology of this research was qualitative research with phenomenological approach. It was a subjective perspective based on the informant's experiences. The data collection was obtained through the informant's frame of mind and their field of experiences as teenagers from divorce family. The writer collected the data through depth interviewing, informants observing and literature reviewing. 


\section{Data Analysis}

In collecting the data, the writer used snowball sampling technique. There were ten teenagers who had become key informants in this research. Many teenagers had the experience of their parents' divorce since they were in kindergarten and elementary school. These are the informants' profile:

Table 1. The Informants Profile Analysis

\begin{tabular}{|c|c|c|c|c|}
\hline $\begin{array}{c}\text { PSEUDONYM } \\
\text { OF MALE } \\
\text { TEENS }\end{array}$ & AGE & $\begin{array}{c}\text { THEIR } \\
\text { PARENTS' } \\
\text { DIVORCE } \\
\text { AT THE } \\
\text { AGE }\end{array}$ & $\begin{array}{c}\text { REASONS TO } \\
\text { DIVORCE }\end{array}$ & $\begin{array}{l}\text { AFTER THE } \\
\text { DIVORCE } \\
\text { FOLLOWING }\end{array}$ \\
\hline Teak & 19 & 15 years old & Abandonment & Mother \\
\hline Pine & 19 & 16 years old & Financial Issue & Mother \\
\hline Palm & 19 & 15 years old & Disharmony & Father \\
\hline Mahogany & 19 & 17 years old & Betrayal & Mother \\
\hline Damar & 20 & 16 years old & Financial Issue & Mother \\
\hline $\begin{array}{l}\text { PSEUDONYM } \\
\text { OF FEMALE } \\
\text { TEENS }\end{array}$ & AGE & $\begin{array}{c}\text { THEIR } \\
\text { PARENTS' } \\
\text { DIVORCE } \\
\text { AT THE } \\
\text { AGE }\end{array}$ & $\begin{array}{l}\text { REASONS TO } \\
\text { DIVORCE }\end{array}$ & $\begin{array}{l}\text { AFTER THE } \\
\text { DIVORCE } \\
\text { FOLLOWING }\end{array}$ \\
\hline Rose & 19 & 16 years old & Betrayal & Mother \\
\hline Jasmine & 19 & 15 years old & Disharmony & Mother \\
\hline Orchid & 19 & 17 years old & Betrayal & Father \\
\hline Ivy & 19 & 17 years old & Disharmony & Mother \\
\hline Lotus & 19 & 17 years old & Violence & Mother \\
\hline
\end{tabular}

Source: Research Result (2015 to 2016)

\section{Finding and Discussion}

Teenagers really need both parents to develop healthy communication family formation. As Simanowitz [5] told about how difficult for teenagers in facing and building their new sense of identity without the help of family. They could have the interpersonal communication with their single parent to communicate each other and build teenagers identity. The support of their single parents in having good interpersonal communication made the teenagers learn to be brave by accepting the new family structure situation.

Without good interpersonal communication, teenagers will be confused to interpret their identity (self-concept). Based on my research result, the 8 teenagers can receive their parent's breakup after the interpersonal communication between single parent and the teenagers run well. They can even digest the reasons of their parents' divorce. But the 2 teenagers in this study keep committing negative actions after parental divorce. The negative actions are done by them to ask for more attention and their nonverbal symbol for the disagreement of parents' divorce. 
Teenagers will observe how parents respond divorce. Negative behaviour can occur in teenagers as the impact of parental divorce. They feel victimized by divorce and the cause of their parents' separation. They display self-injurious actions in order to get the attention of parents. In addition to expect parent's attention, they do bad action in response to their grief over the divorce. These are the categorizations that faced by the teenagers who didn't do effective interpersonal communication with their parents.

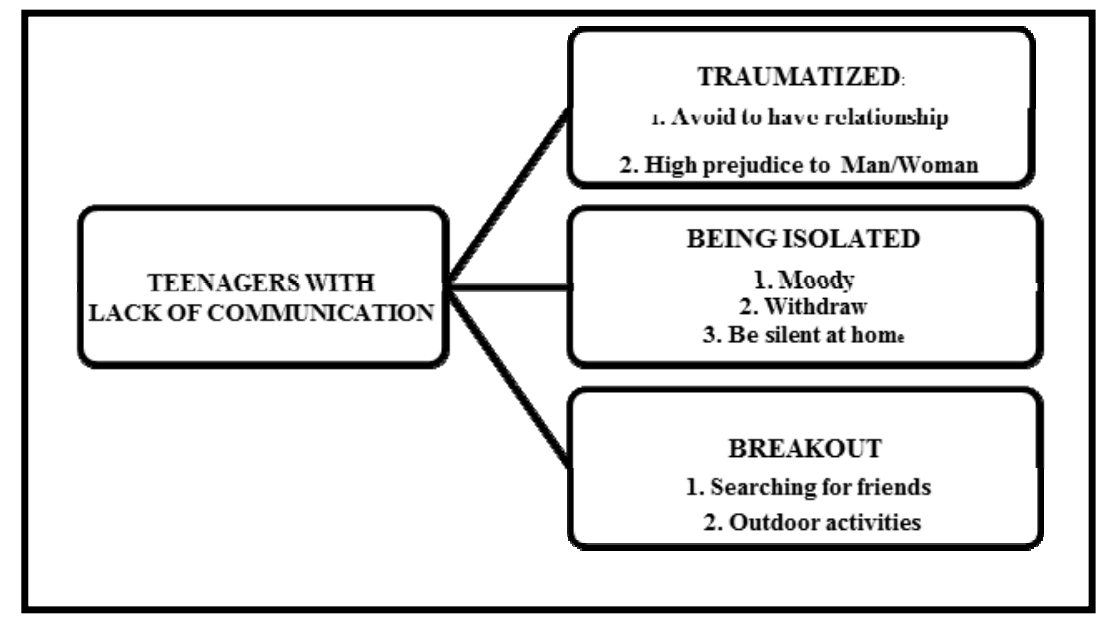

Fig. 1. Negative Teenagers Self Concept from Divorce Family

The role of communication in divorce issues that has been faced by the teenagers are in a prime position. Parents should talk about the reason of the divorce to the teenagers. Actually, they are able to use their logic properly to understand the reasons for the divorce of their parents. The interpersonal communication in the family must be established gradually. The support of their single parents in the form of good communication will make the teenagers learn to be brave by accepting their parents' decision to get divorce.

Effective conversation which occurred in daily talk will shape teenagers confidence. It is established gradually to tighten the relation of each member of the family. At the end, it built positive self-concept to the teenagers by the form of new identity value. This is not only for the teenager, but also for the single parents too.

The interpersonal communication has transformed teenager's perception about having the divorce parents. When having an interpersonal communication, the single parents should focus on the content quality to dive into teenagers mind and heart. There were different functions of having communication skill for the teenager in the family. Teenage girl had personal talk to strengthen the relationship, while teenage boy had the dimension to break the relations up with one of the single parent.

Eventually, the interpersonal communication between single parents and teenagers were transformed to transactional conversation. Teenagers would not feel lonely anymore because their existences were admitted by their single parents. They enter a brand new situation where they finally found their new identity as teenagers from divorce family. This was called the emergence of having an effective interpersonal communication in order to strengthen and support each member of the family.

The teenagers got their new vision on how to face their parents' divorce. They could encounter themselves from this problematic situation. This vision had constantly shaped their self-concept. In the earlier of divorce term, teenagers found it difficult to adapt into a new situation of having single parent. They tend to present negative self-concept. As the years went by, single parents kept making good interpersonal communication. At the end, 
teenagers' self-concept had finally transformed into constructive self-concept. While single parents who never had any talked during and after their divorce with their own teenagers, seemed to have negative self-concept.

\section{Conclusion}

Teenagers need the support of their father or mother in building good interpersonal communication. Interpersonal communication takes an important part to build the gap through losing parents togetherness. It can actually transform them to have good personality in order to avoid the negative effects of divorce. This form of communication is important in order to create a harmonious atmosphere for the establishment of teenagers. They will feel comfortable in communicating their fulfilment of self-actualization to their parents. Good interpersonal communication in divorced family which is done by the single parent will help teenagers to avoid deviant behaviour and destructive behaviours. They really need the figures of a mother and a father as their role model in shaping their self-identity. If it has not been done, they will lose motivation and the support to master their unstable emotions as teenagers.

\section{References}

1. Segrin, Chris, Flora, Jeanne. Family Communication. (London: Lawrence Erlbraum Associates Publishers) (2005)

2. Fagan, Patrick and Aaron Churchill, Journal of Marriage and Religion Research Institute. Washington DC. 202.393.2100. (January 11, 2012).

3. Hewitt, Belinda, Zlatko Skribs, Mark Western, Journal of Australian Sociological Association \& Sociological Association of Aotearoa New Zealand Joint Conference. University of Auckland, New Zealand. 20 (4-7 December 2007).

4. Kasoman, Frank, The Influence of Broken homes on Pupil Academic Performance in Selected Schools in Mbala District: Lessons for School Managers. (Dissertation: University of Zambia) (2012).

5. Simanowitz, Valerie, Peter Pearce. Personality Development. (London: Copyright Licensing Agency Ltd., 2003) 